\title{
Covid-19 lockdown sets wildlife free but increases poaching threats in Nepal
}

\author{
Narayan Prasad Koju ${ }^{1}$, Ram Chandra Kandel ${ }^{2}$, Hari Acharya ${ }^{3}$, Bed Dhakal ${ }^{3}$, and Dinesh \\ Bhuju ${ }^{4}$
}

${ }^{1}$ Nepal Engineering College

23Department of National Park and Wildlife Conservation, Ministry of Forestry and Soil Conservation

${ }^{3}$ Department of National Park and Wildlife Conservation, Ministry of Forestry and Soil

Conservation

${ }^{4}$ Resources Himalaya Foundation, Lalitpur

March 29, 2021

\begin{abstract}
To contain transmission of COVID-19, lockdown or strict restriction of people's mobility outside their residence was imposed worldwide. In Nepal, the first phase of nationwide lockdown was observed from March 24 to July 21, 2020. This sudden halt in human activities brought positive and negative impacts on forests and wildlife. We undertook a study was undertaken to know the impact of the CoViD-19 lockdown on wildlife and forests in the protected areas (PAs) of Nepal. The study was carried in July and September 2020, data of illegal activities recorded by the PAs and also those reported by media were obtained and analyzed. Key Informant Interview (KII) was done with the park officers and security personnel by virtual communication that included telephone, messenger app, and ZOOM video meeting to collect detailed information and for verification. The collected data were categorized into four groups: i) wildlife killed, ii) wildlife injured, iii) arrest incidents related to forest crime, and iv) arrest incidents related to wildlife crime. Data from the fiscal year 2019-2020 were analyzed, comparing before lockdown and after. The study found trends of substantial increases in. wildlife death in two PAs, Banke National Park and Bardia National Park out of 20 during the lockdown. Similarly, Chitwan National Park (CNP) and Shivapuri Nagarjun National Park (SNNP) witnessed a rise in wildlife poaching. CNP and SNNP are located close to highly populated cities and also having human settlements in their peripheries. Interestingly, wildlife was easily sighted inside PAs during the lockdown, presumably because the absence of visitors and human activities during the lockdown decreased disturbance. Thus, a paradoxical situation was observed with the wildlife enjoying the freedom of movement on the one hand, but with poachers, many of them laid off from other activities, taking advantage of the lapse in security.
\end{abstract}

\section{Hosted file}

manuscript.pdf available at https://authorea.com/users/404654/articles/515771-covid-19lockdown-sets-wildlife-free-but-increases-poaching-threats-in-nepal 

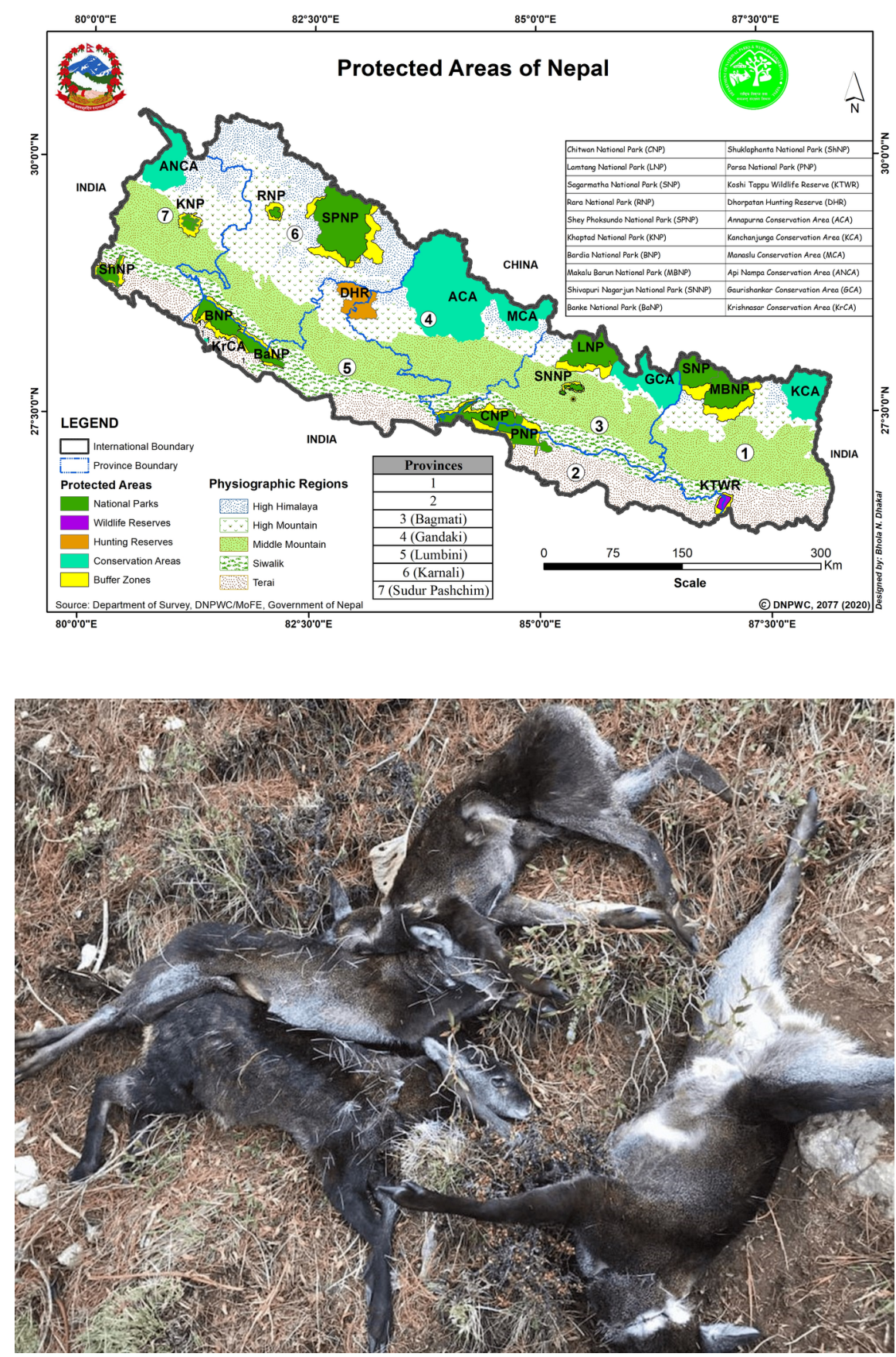


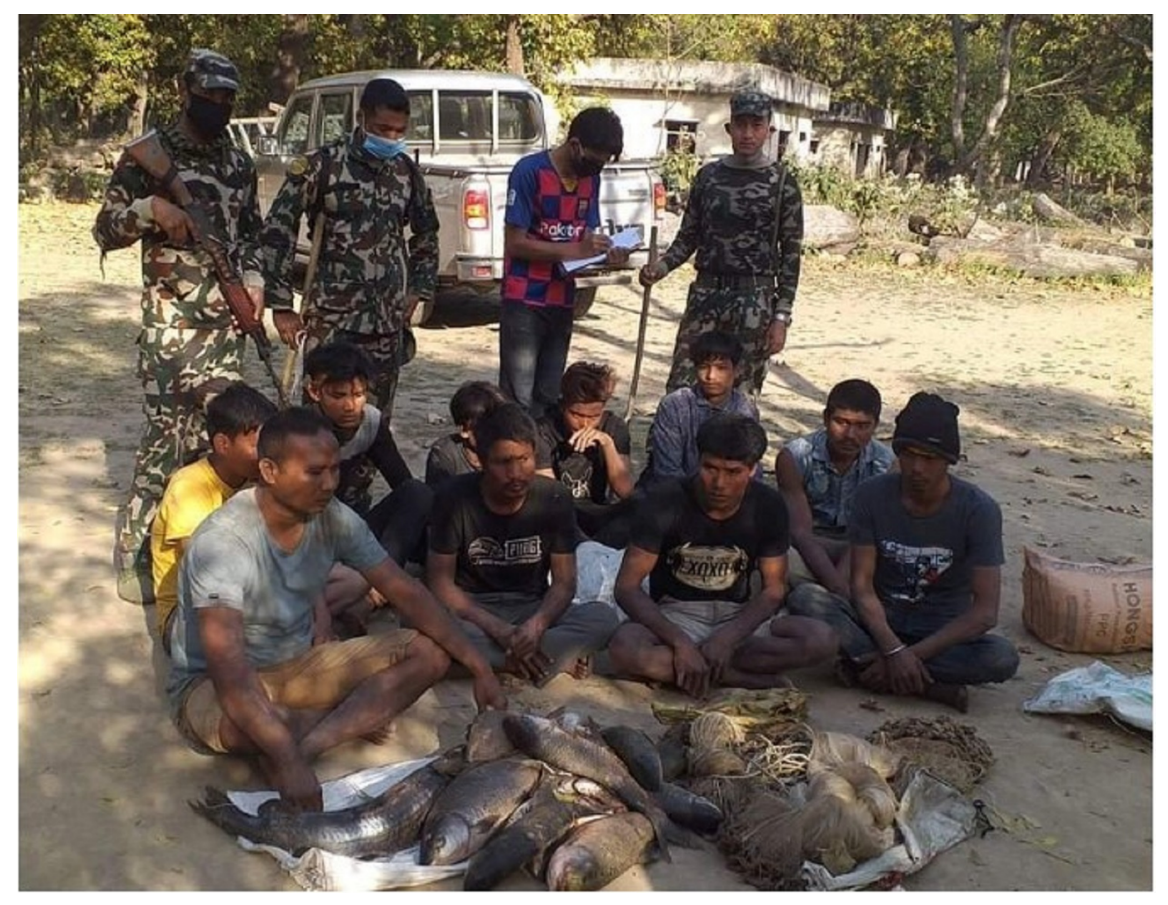

